\title{
Impact of Atrazine Disposal on the Water Resources of the Yang River in Zhangjiakou Area in China
}

\author{
Ren Jin, Jiang Ke
}

Research Center For Eco-Environmental Science, Academia Sinica, Post Office Box 2871, Beijing, 100085, China

Received: 1 October 2001/Accepted: 7 January 2002

Atrazine is one of the most widely used herbicides in the world. Because of its high water solubility and persistence in the environment, it can contaminate the water source via diffusion and leaching during its application. Atrazine has been identified as a potential pollutant in drinking water and also been listed as an endocrine disrupting chemical by the EU and the US EPA (Ren et al. 2001). Atrazine shows an exposure response relationship with the Daphnia sex ratio (Dodson et al. 1999), and can exert a weak cytotoxic effect (Rabis et al., 1998). Van Leeuwen and coworkers show that the level of atrazine (range $0.05-0.6 \mu \mathrm{g} / \mathrm{L}$ ) has been directly associated $(\mathrm{P}<0.05)$ with stomach cancer incidence. (Van Leeuwen et al .1998)

Although the use of atrazine has been restricted in Switzerland for ten years and was banned in Italy and Germany recently, it is still one of the most popular herbicides. The maximum contaminant level (MCL) for atrazine in drinking water established by the US EPA is $3 \mu \mathrm{g} / \mathrm{L}$, and the European Union requires the MCL below $0.1 \mu \mathrm{g} / \mathrm{L}$ for a single pesticide in drinking water. The Chinese government issued the same MCL requirement for atrazine in drinking water as the US EPA in 1998. Atrazine is often detected in surface water and groundwater in many countries. A national water-quality assessment (NAWQA) study showed that atrazine was the most frequently detected compound, with 38 percent of water samples from 1034 sites across the US testing positive (i.e., the atrazine concentration in several sites exceeded the MCL (D W Kolpin et al., 1998)). Atrazine is also the major contaminant and its level often exceeds the value of $0.1 \mathrm{ppb}$ in the three main rivers in Paris (Tisseau et al., 1999).

In China, atrazine was produced and used in the 1980's and its usage has increased every year. The total quantity of product is up to 5000 tons per year. Several cases involved with serious atrazine contamination have been reported. A number of studies investigated the atrazine contamination condition, but the influences of atrazine on drinking water and groundwater have not been investigated in China. 


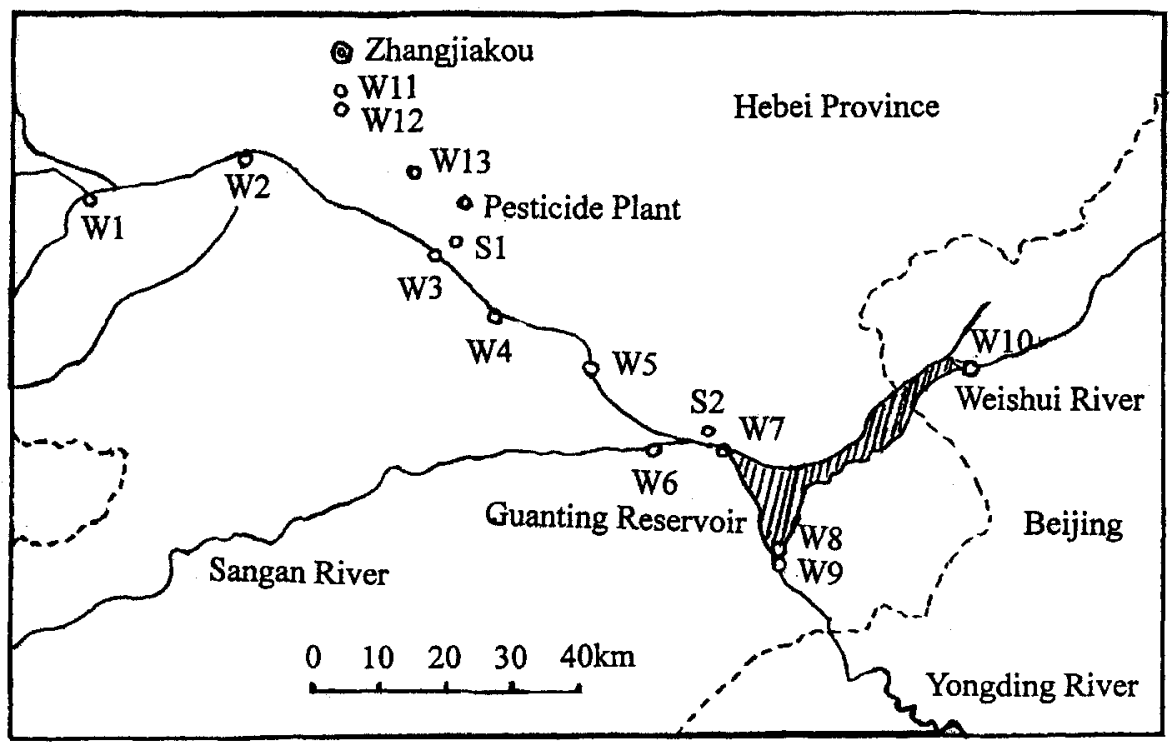

Figure 1 Map of Yang River with sampling sites

W1: Nan Yang River, W2: Zuwei bridge at Yang River, W3: Discharge sites at Yanghe river, W 4: Xaingshuipu at Yang River, W5: Jimingyi at Yang Rriver, W6: Wenquantun at Sanggan River, W7: Bahaoqiao at Yang River, W8: Baqian at Guanting Reservoir, W9: Bahou at Guanting Reservoir, W10: Weishui River W11, W12: Detector well (200-300m) in Zhangiakou district, W13: Shallow layer well near the Yang River in Zhangilakou district

S1: Discharge sites at Yang River, S2: Bahaoqiao at Yang River

The goal of the current study is to investigate the distribution of atrazine in the Yang River and Guanting Reservoir (Figure 1). The Yang River is located northwest of Beijing. It is about $59.4 \mathrm{~km}$ in length and flows through Zhangjiakou district in the north Hebei Province of China, pouring into Guanting Reservoir, which is one of the two major water resources of Beijing. The local climate belongs to the semi-arid environment and the annual average rainfall in this area is about $340-400 \mathrm{~mm}$. The annual evaporation capacity is $1939.5 \mathrm{~mm}$. The Yang River is the major surface water source of local population. Due to the overuse of groundwater, the government has planned to improve the water quality in Guanting Reservoir and make it applicable as a source of drinking water.

The current study employs solid phase extraction ( SPE ) prior to liquid chromatography ( LC ) on-line coupling with mass spectrometry ( MS ) to analyze water samples for atrazine from the Yang River. Furthermore, ultrasonic extraction 
and SPE using a mixed sorbent cartridge were conducted to detect atrazine in sediment samples. Finally, the impact of atrazine level on the quality of drinking water in the Yang River and the Guanting Reservoir was evaluated.

\section{MATERIALS AND METHODS}

Figure 1 shows the sampling locations. The water samples of the Yang River were collected at upstream, midstream, and downstream points of the river during 1999 and 2000. The groundwater sample was collected in April and May 2000, from a deep detector well $(200-300 \mathrm{~m})$ of Zhangjiakou city and a farmer's shallow well $(30 \mathrm{~m})$. Water samples were kept in clean glass bottles and stored in a refrigerator at $4^{\circ} \mathrm{C}$ before being analyzed. Sediment samples (upper $5 \mathrm{~cm}$ ) were collected from the sites where chemical manufacturers discharge waste into the Yang River and the point that the Yang River converges into the Guanting Reservoir. Sediments were air dried and sieved.

Atrazine was detected using the SPE on-line LC-MS method. The HPLC system (HP1050) was equipped with a mass spectrometry detector (Micromass Plantform II) running in selective ion monitoring mode using the ions $m / z 216$ and 218 . Solid-phase extraction cartridges used for off-line extraction were MCX cartridges (Waters, $3 \mathrm{~cm} 60 \mathrm{mg}$ ). Pre-column for on-line use was $4 \times 3 \mathrm{~mm}$ I.D. cartridge packed with C18 particles( Phenomena, USA). Waters $510^{\prime}$ constant velocity pump (provided by Waters. Co) was used to deliver the water samples. The mass spectrometer was equipped with an APCI source. Scan range was from $\mathrm{m} / \mathrm{z} 100$ 430 (positive mode), the scan period was $0.3-1.05 \mathrm{~s}$. Separation was performed on a Vydak C18 column ( $5 \mu \mathrm{m} 150 \mathrm{X} 4.6$ i.d.mm). The mobile phase was acetonitrile/ water $(50 / 50)$ and the flow rate was $0.8 \mathrm{ml} / \mathrm{min}$. UV detector was set at $220 \mathrm{~nm}$.

For calibration a blank water sample was spiked with atrazine. Water samples were filtered before extraction. The cartridge was conditioned with $3.0 \mathrm{ml}$ acetonitrile and rinsed with $3 \mathrm{ml}$ mobile phase (acetonitrile/water 40/60) prior to preconcentration. Then $10-50 \mathrm{ml}$ samples were passed through the cartridge at a flow rate of $5 \mathrm{ml} / \mathrm{min}$. After preconcentration, the analyses were eluted from the cartridge to the analytical column with the mobile phase and detected by the UV and mass spectrometric detector. Determination limit was $0.01 \mu \mathrm{g} / \mathrm{L}$ for atrazine in water (Huang C L et al. 2000).

Sediment samples of $5-10 \mathrm{~g}$ were extracted three times $(10,8,8 \mathrm{~min})$ with LC-grade water(20, 20, 15ml) using an ultrasonic extractor. The extracted liquid was combined and centrifuged. The supernatant was adjusted to $\mathrm{pH} 1.5$ with $\mathrm{HCl}$. The MCX cartridge was conditioned with $3 \mathrm{ml}$ methanol followed by $3 \mathrm{ml}$ water. The aqueous solution was loaded on the cartridge. The cartridge was rinsed with $2 \mathrm{ml}$ 


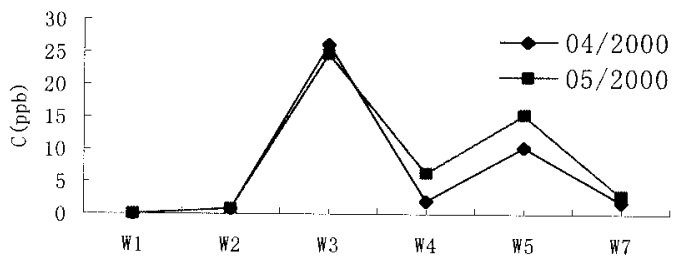

Figure 2, Distribution of atrazine in the water of the Yang River.

pure water $(\mathrm{pH}=2)$, methanol, and $2 \% \mathrm{NH}_{3} \cdot \mathrm{H}_{2} \mathrm{O}$, and atrazine was eluted with $3 \mathrm{ml} 4 \% \mathrm{NH}_{4} \mathrm{OH}$ in methanol. The eluent was concentrated to approximately 100 $\mu 1$ with a gentle stream of $\mathrm{N}_{2}$ at room temperature. The $10 \mu 1$ sample was injected into the LC system . Determination limit was $1 \mu \mathrm{g} / \mathrm{L}$.

\section{RESULTS AND DISCUSSION}

The most common method employed for analysis of herbicides is GC and HPLC. GC-MS offers good sensitivity and similar selectivity as HPLC-MS. However, there are some problems to develop on-line SPE-GC-MS method, the trace water in solvent and analyses need to be removed, so we analyzed the water samples by SPE-LC-MS method.

Figure 2 shows the concentration of atrazine in the Yang River surface water samples in April and May 2000. The values ranged from 0.22 to $26.1 \mu \mathrm{g} / \mathrm{L}$. The highest value was observed at W3. A pesticide manufacturing plant that primarily produces atrazine is located at upstream of the Yang River. The treated wastewater of this factory was directly discharged into the Yang River at W3. The factory is the earliest plant that produced atrazine in the $1980 \mathrm{~s}$, and the annual average output currently is up to 700 tons. The long-term disposal of waste will unavoidably affect the quality of the water in the Yang River.

No residual atrazine was detected in $W 1$, which is located upstream and away from W3. The value of atrazine concentration in W2, which is located between W1 and $\mathrm{W} 3$ points, and further away from $\mathrm{W} 3$, is about $0.8 \mu \mathrm{g} / \mathrm{L}$. It was surprising that we detected atrazine at this sampling point, which raises the possibility that a nearby small herbicide manufacturer might dispose of its waste to the river.

With the increment of distance with respect to $\mathrm{W} 3$, the concentration of atrazine in sampling spots W4, W5 and W7 decreases accordingly. There is no pollution source between W4 and W5, but there is an irrigating canal at W5, and the canal always has much more water than the river. We sampled the canal because the Yang River was close to dry. With a dam in the canal at W5, the water in the canal flowed slowly and evaporated and concentrated gradually. Thus, the concentration of W5 


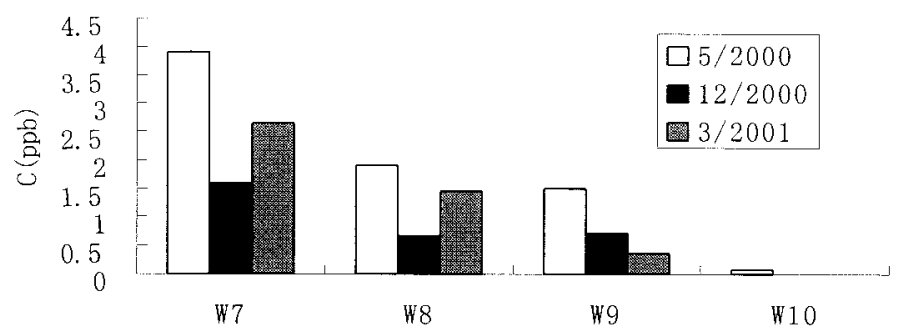

Figure 3. Distribution of residual atrazine in Guanting Reservoir

was twice higher than the results of W4. When the samples of W5 were taken from the river in other months, the value of atrazine concentration was close to that of W4.

The concentration of atrazine at W7 located at the entrance of the Yang River to the Guanting Reservoir is much lower than that of the two spots upstream. Sanggan River, converging into the Yang River at W6 contains atrazine at a level lower than $0.1 \mu \mathrm{g} / \mathrm{L}$, showing that the Sanggan River has little residual atrazine and has diluted the atrazine concentration of the Yang River.

The other rivers converging into the Yang River have been dry for several years, so they do not contribute to the atrazine level in the Yang River. According to the available information, the farmers in the area do not apply herbicides to their fields, which excludes the possibility of herbicides being the cause of the quality of the water in the river. Therefore, we conclude that the atrazine pollution in the Yang River was primarily caused by the disposal of pesticide plant.

The seasonal variability of atrazine concentration is shown in Table1. In rainy season, the atrazine was diluted and the concentrations of atrazine in samples collected from different sites (W2, W4, W5, W7) show no significant difference. The level ranged from $0.22-0.60 \mu \mathrm{g} / \mathrm{L}$, the mean value being $0.36 \mu \mathrm{g} / \mathrm{L}$. In dry season, the atrazine concentration of different sites was higher due to lower precipitation and rapid evaporation. The level ranged from 0.67 to $2.59 \mu \mathrm{g} / \mathrm{L}$, the mean value being $1.78 \mu \mathrm{g} / \mathrm{L}$. The value of several sites exceeded the limit $(3 \mu \mathrm{g} / \mathrm{L})$. During this season, the farmland was irrigated by water from the Yang River. Under the arid and hot weather, the concentration of atrazine was elevated due to evaporation and may cause harmful effects to the growth of the crops.

Concentration of atrazine in upper sediments showed no significant difference from that of atrazine in water samples collected at the same sites. The atrazine concentration in sediment was $19 \mu \mathrm{g} / \mathrm{L}$ in S1 and $3 \mu \mathrm{g} / \mathrm{L}$ in S2, $25 \mu \mathrm{g} / \mathrm{L}$ and $2 \mu \mathrm{g} / \mathrm{L}$ in water samples collected at spots $\mathrm{W} 3$ and $\mathrm{W} 7$ from the same area, indicating that an 
Table 1. the distribution of atrazine in the Yang River $(\mu \mathrm{g} / \mathrm{L})$

\begin{tabular}{cccccc}
\hline mon/y & $9 / 1999$ & $11 / 1999$ & $7 / 2000$ & $10 / 2000$ & $11 / 2000$ \\
\hline W2 & 0.29 & 3.84 & 1.4 & ND & 0.19 \\
W4 & 0.60 & 1.09 & 4.42 & 3.44 & 1.41 \\
W5 & 0.32 & 2.21 & 2.06 & 0.57 & 1.64 \\
W7 & 0.22 & 0.89 & 0.26 & ND & 1.52 \\
\hline
\end{tabular}

ND: not detected

equilibrium of atrazine was reached between water and upper sediment. Even though the herbicide plants may not always discharge sometimes, the level of atrazine in the Yang River would stay above $0.1 \mu \mathrm{g} / \mathrm{L}$ due to the transport from sediment interface to water as well as its tendency to transport to ground water by diffusion. The low $\mu \mathrm{g} / \mathrm{L}$ level of residual atrazine also agrees well with its high solubility in water and low absorption capacity in sediment.

Most of the groundwater of Zhangjiakou district comes from atmospheric precipitation. After precipitation, permeation and the ground runoff, or permeation of irrigating canals and surface water supplied the water. This condition makes atrazine amenable to permeate groundwater so as to influence the quality of the drinking water, causing the contamination.

The water samples from shallow layer of groundwater $(\mathrm{W} 13,30 \mathrm{~m})$ and deepwater detector well (W11 and W12, $200-300 \mathrm{~m}$ ) were monitored. The concentration of atrazine in shallow-layer water was $0.69 \mathrm{\mu g} / \mathrm{L}$ and wasn't detected in deep-layer water. The results showed that atrazine disposal by pesticide plant has permeated shallow layer water, however, it was not long enough in time and not enough in quantity to cause dramatic effect on the deep layer underground water. If such discharge continues, with the continuous permeation of atrazine into ground water, the contamination will certainly become more and more serious. Therefore, it is necessary to restrict the use and discharge of atrazine. Also, according to the standard value of $0.1 \mu \mathrm{g} / \mathrm{L}$ atrazine issued by the $\mathrm{EU}$, the atrazine level in shallow layer groundwater has already exceeded the limit.

The atrazine residual level in Guanting Reservoir is shown in Figure 3. Atrazine was detected in most area of this reservoir, with the values at entrance (W7, W10) and exit (W8, W9) ranging from $0.8-1.8 \mu \mathrm{g} / 1$ for dry season and $0.6-0.75 \mu \mathrm{g} / 1$ for rainy season. The concentration in dry season was higher than that of rainy season. The site of the plant discharge is $\mathbf{4 5}$ miles away from the entrance of the reservoir. The Weishui River is another source of Guanting Reservoir and the atrazine concentration of W10 is lower than the MCL. The Yang River should be the only pollution source of atrazine for Guanting Reservoir. 
The total amount of atrazine in Guanting Reservoir can be estimated by the following calculations. Given that the storage capacity of the reservoir was about $4.38 \times 10^{8} \mathrm{~m} 3$ in May 2000 , the amount of atrazine was about $0.66 \mathrm{~kg}$ according to the average concentration of atrazine at the point of exit. The amount of atrazine was about $0.25 \mathrm{~kg}$ in December 2000 with $4.14 \times 10^{8} \mathrm{~m}^{3}$ of storage capacity. Between rainy season, June to September 2000, $1.0 \times 10^{8} \mathrm{~m}^{3}$ water from the reservoir was discharged, and between October and December, $1 \times 10^{8} \mathrm{~m}^{3}$ water was recharged from Baihe bi Reservoir to minimize the amount of water lost. The water of Guanting Reservoir was diluted in December 2000. Nonetheless, the trace residual atrazine will last for a long time in the reservoir if the pesticide plant continues to discharge its waste to the river and the waste accumulates over time. This situation would unavoidably affect the water quality of Guanting Reservoir in Beijing. Therefore, this issue should be addressed with significant caution and attention.

In summary, atrazine was detected in the large area of the Yang River and Guanting Reservoir resulting from the contribution of a point source. The level of atrazine ranged from 0.22 to $26.1 \mu \mathrm{g} / \mathrm{L}$. Atrazine was also found in shallow-level of groundwater though the concentration was lower than the standard of the EU. The total amount of atrazine in Guanting Reservoir ranged from $2.5-6.6 \mathrm{~kg}$. Obviously, a strict requirement should be enforced to limit the discharge of pesticide plants.

Acknowledgments. Primary financial support for this research was provided by the National Natural Science Foundation of China (No. 29977023) and the Chinese Academy of Sciences (No. KJ951-A1-507).

\section{REFERENCES}

Dodson S L, Merritt C M, Shannahan J P, Shults C M. (1999) Low exposure concentrations of atrazine increase male production in Daphnia pullcaris. Environ Toxicol and Chem 18:1568-1573

Dana W Kolpin, Jack E Barbash, Robert J Gilliom.(1998) Occurrence of pesticides in shallow groundwater of the Unite States: Initial results from the national water-quality assessment program. Enviro Sci Technol 32:558-566

John R Dean, Gerorge W, Ian J Barnabas (1996) Determination of triazine herbicides in environment sample. J of Chrom A 733:295-355

Huang C L, Wen M J, Ke J. (Suppl. 2000) Analysis of trace herbicides in water by SPE-LC-MS. Chinese J Anal Lab 19:6-9

Ribas G, Surralles J, Carbonell E, Creus A, Xamena N, Marcos R. (1998) Lack of genotoxicity of the herbicide atrazine in cultured human lymphocytes. Mutation Research-genetic. Toxicol Environ Mut 416:93-99

Ren J, Jiang K. (2001) Progress in Research of Endocrine Disrupting Chemicals. 
Prog in Chem 13:135-144

Tisseau M A, Fauchon N, Vandevelde T. (1999) Assessing pesticides contamination of the rivers in the Paris area. Tech Sci Meth, Genie UrbainGenie Rural 9:54-59

Van Leeuwen J A, Waltner-Toews D, Abernathy T, Smit B, Shoukri M. (1999) Associations between stomach cancer incidence and drinking water contamination with atrazine and nitrate in Ontario (Canada) agroecosystems.1987-1991. Int J Epidemio 28:836-840 